\title{
Induced Fusion of Fungal Protoplasts following Treatment with Polyethylene Glycol
}

\author{
By J. ANNÉ \\ Department of Microbiology, Rega Institute, \\ Katholieke Universiteit te Leuven, B-3000 Leuven, Belgium \\ AND J. F. PEBERDY \\ Department of Botany, University of Nottingham, Nottingham NG7 $2 R D$
}

(Received 17 April 1975; revised I October 1975)

INTRODUCTION

Although protoplast fusion is of current interest because of its possibilities in pure and applied genetics, only a few reports exist on intraspecific fusion between fungal protoplasts and subsequent selection of heterokaryons. Naturally-occurring fusion between protoplasts of Geotrichum candidum (Ferenczy, Kevei \& Zsolt, 1974) and Aspergillus nidulans (Ferenczy, Kevei \& Szegedi, I 975) has been reported. Binding \& Weber (1974) described fusion between protoplasts of Phycomyces blakesleeanus induced by seawater or calcium ions at high $\mathrm{pH}$, but the frequency of heterokaryon formation was low in all cases. We here report heterokaryon formation, at high frequency, after induced intraspecific fusion between protoplasts of auxotrophs of Penicillium chryosogenum, P. patulum, P. roquefortii, A. nidulans, A. niger and Cephalosporium acremonium, and fusion between protoplasts of $P$. chrysogenum and $P$. notatum auxotrophs, using solutions containing polyethylene glycol (PEG) mol.wt. 6000 .

\section{METHODS}

Organisms and growth conditions. Auxotrophic mutants of Penicillium chrysogenum Wis. 49-2105, P. roquefortii (University of Nottingham Collection) and mutant 8650 of Cephalosporium acremonium ATCCII550 were selected after $N$-methyl- $N$-nitro- $N$-nitrosoguanidine treatment (Adelberg, Mandel \& Chen, 1965) and checked for their stability over several vegetative generations. An auxotrophic strain of Penicillium notatum Imi38632 was obtained from the Commonwealth Institute, Kew, Surrey, and Aspergillus nidulans mutants GO4O (biAI; wA3; arg-9) and GoII $2\left(y A_{2}\right.$; pyro A4; methB 3$)$ were obtained from the Department of Genetics, University of Glasgow. Penicillium patulum auxotrophs were kindly supplied by Mr A. R. Cottrell (ICI Ltd, Manchester) and mutants of Aspergillus niger by Dr I. H. Pallett (Beecham Pharmaceuticals, Surrey).

All strains were maintained on a complete medium (Anné, Eyssen \& De Somer, 1974), except $A$. nidulans and $A$. niger which were grown on Vogel's medium N (Vogel, I964) supplemented with glucose ( $10 \mathrm{~g} / \mathrm{l})$, Difco Bacto-peptone $(5 \cdot 0 \mathrm{~g} / \mathrm{l})$, Difco yeast extract $(2.5 \mathrm{~g} / \mathrm{l})$ and the specific requirements for the strains (biotin, $0.02 \mathrm{mg} / \mathrm{l} ;$ pyridoxine, $0.5 \mathrm{mg} / \mathrm{l}$; arginine, $200 \mathrm{mg} / \mathrm{l}$; methionine, $50 \mathrm{mg} / \mathrm{l}$; inositol, $0.5 \mathrm{mg} / \mathrm{l}$ ), and $C$. acremonium which was grown on a complete sporulation medium (Lemke \& Nash, 1972).

Mutant symbols. Strains with different requirements and spore colour were used. The 
symbols for the mutants other than $A$. nidulans were as follows: whi (white spore colour); $y l o$ (yellow spore colour); met (methionine); cys (cysteine); met/cys (methionine or cysteine); lys (lysine); prolarg (proline or arginine); leu (leucine); met/thr (methionine or threonine); val (valine); trp (tryptophan); ino (inositol); pyr (pyridoxine).

Protoplast formation and fusion treatment. Protoplasts from Penicillium, Cephalosporium and Aspergillus were prepared as described previously (Anné et al., 1974; Peberdy \& Gibson, 197I), and separated from mycelial debris by filtration through a sintered glass filter (porosity 1). After washing in $0.7 \mathrm{M}-\mathrm{NaCl}$, protoplasts were mixed $\left(5 \times 10^{6}\right.$ to $10^{7}$ protoplasts of each auxotroph) and centrifuged $(700 \mathrm{~g}$, $10 \mathrm{~min})$. The pelleted protoplasts were suspended in $\mathrm{I} \mathrm{ml}$ of a pre-warmed $\left(30^{\circ} \mathrm{C}\right)$ solution of $30 \%(\mathrm{w} / \mathrm{v})$ PEG (Koch-Light) in $0.01 \mathrm{M}-\mathrm{CaCl}_{2} .2 \mathrm{H}_{2} \mathrm{O}$ and $0.05 \mathrm{M}$-glycine, adjusted to $\mathrm{pH} 7.5$ with $0.0 \mathrm{I} \mathrm{M}-\mathrm{NaOH}$. After incubation for $10 \mathrm{~min}$ at $30^{\circ} \mathrm{C}$ the suspension was diluted with $6 \mathrm{ml}$ of minimal medium adjusted to $0.6 \mathrm{~m}-\mathrm{NaCl}(\mathrm{MM})$ (Anné et al., 1974), and centrifuged (700 g, $5 \mathrm{~min}$ ). Protoplasts were twice washed with $8 \mathrm{ml}$ portions of $0.6 \mathrm{M}-\mathrm{NaCl}$ and finally resuspended in $5 \mathrm{ml}$ of $0.7 \mathrm{M}-\mathrm{NaCl}$. Serial dilutions were plated on solid $\mathrm{MM}$ to select nutritionally-complementing fused protoplasts. The total number of viable protoplasts before and after PEG treatment was determined by plating on solid MM supplemented with $0.2 \%$ Difco yeast extract (PM). All plates were incubated at $30^{\circ} \mathrm{C}$.

\section{RESULTS AND DISCUSSION}

Immediately after the PEG solution was added, protoplasts adhered firmly and shrank, indicating the high osmotic pressure of the solution. During the subsequent dilution with $\mathrm{MM}$, protoplasts regained their normal size although larger bodies were also observed which were assumed to originate from two or more fused protoplasts. Many protoplasts still adhered, but these protoplast aggregates separated completely after removal of PEG by the $\mathrm{NaCl}$ washes and still more fused protoplasts were then observed. PEG had no aggregating influence on fungal spores or mycelium.

Fusion between protoplasts of nutritionally-complementing strains was detected by formation of heterokaryons developing on solid MM. After 48 to $72 \mathrm{~h}$, colonies appeared from PEG-treated mixed protoplasts on both MM and PM. Unfused protoplasts, spores or mycelium are unable to develop on these media, even after mixing the auxotrophic mutants at high density ( $10^{7}$ spores or protoplasts on one plate), except that if protoplasts of $A$. nidulans or $P$. patulum auxotrophs were mixed and plated at high density $\left(>10^{6}\right)$ then cross-feeding occurred. However, at lower densities $\left(<\mathrm{IO}^{5}\right)$ no growth was observed on control plates. If protoplasts of the auxotrophic strains were separately treated with PEG solution, washed and then mixed before plating, again no heterokaryon formation was observed.

Fusion experiments between protoplasts of several auxotrophic mutants were done. The frequency of fusion, based on the ratio of the number of colonies developing on $\mathrm{MM}$ and on PM after PEG treatment, was $0 . \mathrm{I}$ to $0.7 \%$, as determined from several experiments (Table 1). Comparison of numbers of protoplasts regenerating on PM, before and after PEG treatment, showed that only about $10 \%$ of the protoplasts survived (Table I). This loss of viability was probably due to lysis of protoplasts by PEG.

Colonies on MM sporulated after 4 to 6 days at $30^{\circ} \mathrm{C}$ to give a mixture of spores of the two component strains used in the fusion treatment, and were identified as heterokaryons (Pontecorvo, 1956). In fusion experiments, using $P$. chrysogenum white and yellow nutritionally-complementing strains, some green sectors and outgrowths appeared in the mixed 
Table I. Frequencies of heterokaryon formation before and after fusion treatment of mixtures of protoplasts of auxotrophic strains of different fungi

Fusion treatment was carried out by suspending the protoplasts in solutions containing $30 \%$ (w/v) PEG, $0.01 \mathrm{M}-\mathrm{CaCl}_{2} .2 \mathrm{H}_{2} \mathrm{O}$ and $0.05 \mathrm{M}$-glycine, $\mathrm{pH} 7.5\left(30^{\circ} \mathrm{C}\right.$, $\left.10 \mathrm{~min}\right)$; after washing, dilutions were plated on to hypertonic $\mathrm{MM}$ and $\mathrm{PM}$.

\begin{tabular}{|c|c|c|c|c|c|}
\hline \multirow[b]{3}{*}{ Fusion mixtures } & \multicolumn{2}{|c|}{$\begin{array}{c}10^{3}<\text { Heterokaryon } \\
\text { formation } / \mathrm{ml} \\
\text { on } \mathrm{MM}\end{array}$} & \multicolumn{2}{|c|}{$\begin{array}{l}10^{-6} \times \text { Protoplasts } \\
/ \mathrm{ml} \text { regenerating } \\
\text { on PM }\end{array}$} & \multirow{3}{*}{$\begin{array}{l}\text { Fusion } \\
\text { frequency } \\
(\%)\end{array}$} \\
\hline & Before & After & Before & After & \\
\hline & PEG & PEG & PEG & PEG & \\
\hline \multicolumn{6}{|l|}{ P. chrysogenum } \\
\hline lys prolarg whi + leu met/cys ylo & 0 & $18 \cdot 2$ & $28 \cdot 2$ & 3.5 & 0.52 \\
\hline lys prolarg whi + lys met whi & o & 0.0 & $33 \cdot 6$ & 3.62 & 0.00 \\
\hline lys prolarg whi + leu met/thr ylo & o & $22 \cdot 0$ & $24 \cdot 8$ & $3 \cdot 10$ & 0.70 \\
\hline leu met/thr ylo + lys met whi & o & $10 \cdot 7$ & $18 \cdot 6$ & $2 \cdot 20$ & $0 \cdot 48$ \\
\hline \multicolumn{6}{|l|}{$P$. patulum } \\
\hline$m e t+p y r$ & $\mathrm{O}^{*}$ & $3 \cdot 8$ & $\mathrm{NC}$ & $2 \cdot 3$ & 0.17 \\
\hline$m e t+$ ino & $\mathrm{O}^{*}$ & $5 \cdot 7$ & $\mathrm{NC}$ & $2 \cdot 7$ & $0 \cdot 27$ \\
\hline$p y r+i n$ & $0^{*}$ & 13.0 & $\mathrm{NC}$ & $2 \cdot 0$ & 0.65 \\
\hline \multicolumn{6}{|l|}{ P. roquefortii } \\
\hline$v a l+l y s$ & o & $6 \cdot 0$ & $\mathrm{NC}$ & $3 \cdot x$ & 0.19 \\
\hline \multicolumn{6}{|l|}{ A. nidulans } \\
\hline GO4O + GOII2 & $0^{*}$ & $2 \cdot 15$ & $10 \cdot 8$ & $0 \cdot 79$ & 0.27 \\
\hline \multicolumn{6}{|l|}{ A. niger } \\
\hline met + ino & 0 & 0.8 & $2 \cdot 8$ & $0 \cdot 36$ & 0.22 \\
\hline \multicolumn{6}{|l|}{ C. acremonium } \\
\hline$c y s+m e t$ & o & $24 \cdot 5$ & $71 \cdot 0$ & $7 \cdot 0$ & 0.35 \\
\hline$c y s+p y r$ & o & $58 \cdot 5$ & $15 \cdot 0$ & $15 \cdot 0$ & 0.39 \\
\hline$c y s+t r p$ & o & $42 \cdot 5$ & $15 \cdot 0$ & $10 \cdot 0$ & 0.42 \\
\hline$m e t+t r p$ & o & $9 \cdot 0$ & $6 \cdot 4$ & $5 \cdot 0$ & $0 \cdot 18$ \\
\hline \multicolumn{6}{|l|}{$P$. chrysogenum $+P$. notatum (cys ylo) } \\
\hline lys pro/arg whi + cys ylo & 0 & $9 \cdot 22$ & $52 \cdot 5$ & $5 \cdot 05$ & 0.18 \\
\hline leu metithr ylo + cys ylo & o & $4 \cdot 50$ & $60 \cdot 0$ & 3.60 & $0 \cdot 12$ \\
\hline lys met whi + cys ylo & 0 & $5 \cdot 10$ & $47 \cdot 5$ & $4 \cdot 80$ & 0.11 \\
\hline leu met/cys ylo + cvs ylo & 0 & 0.00 & $40 \cdot 5$ & $4 \cdot 70$ & 0.00 \\
\hline
\end{tabular}

$\mathrm{NC}$, Not counted. $\quad *$ Only at low plating densities $\left(\leqslant 10^{4}\right.$ protoplasts on a plate $)$.

white-yellow colonies after 7 to 10 days' incubation. These sectors were confirmed as diploid by prototrophy and the colour of their spores (Pontecorvo, 1956) and by spore size and their doubled DNA content (Pontecorvo \& Sermonti, 1954; MacDonald, Hutchinson \& Gillett, 1965). Haploid and diploid spores, respectively, had mean diameters of 2.95 and $3.60 \mu \mathrm{m}$, and contained 2.0 and $4.3 \mathrm{\mu g} \mathrm{DNA} / 10^{8}$ spores (following the DNA extraction method of Heagy \& Roper, 1952). Natural segregants appeared as rare white-yellow spots or sectors of auxotrophic spores in colonies of single spore isolates of the diploids on complete medium. Segregation patterns are now under investigation.

To show the versatility of PEG as a fusogenic agent in fungi other than P. chrysogenum, intraspecific heterokaryons were induced by PEG treatment of protoplasts of different auxotrophic species such as $P$. patulum, $P$. roquefortil, $A$. nidulans, $A$. niger and $C$. acremonium (Table 1). The fusion frequencies were always about the same.

These results demonstrated that heterokaryon formation on $\mathrm{MM}$ was obtained by fusion 
of protoplasts, and was not due to cross-feeding and subsequent anastomosis between regenerating protoplasts. Fusion frequency was the same for species such as $A$. nidulans which easily form heterokaryons, as for species such as $C$. acremonium in which the heterokaryotic condition is not easily achieved by conventional methods (Nüesch, Treichler \& Liersch, 1973). Also, no differences in fusion frequency were shown on MM plates with high $\left(\geqslant 10^{4}\right)$ or with low $\left(<10^{3}\right)$ protoplast densities. If cross-feeding had occurred, plates with a larger number of protoplasts should have shown a higher fusion frequency, for they provide more opportunities for cross-feeding or for contact between germ tubes of regenerating protoplasts than do plates with a limited number of well-distributed protoplasts.

Heterokaryons between $P$. chrysogenum and $P$. notatum after PEG treatment may have shown that interspecific fusion can take place between closely related species, except that there is some doubt as to whether these are distinct species (Onions, personal communication).

Using $P$. chrysogenum, we also found heterokaryon formation after treatment of mixed auxotrophic protoplasts with polyethylene glycol of molecular weight I 540 or 4000 (Kao \& Michayluk, 1974) and with calcium ions at high pH (Keller \& Melchers 1973)-methods used for fusion between higher plant protoplasts - but frequencies were much lower. After treatment of protoplast mixtures with solutions of polyethylene glycol of molecular weights 6000 , 4000 or 1540 , fusion frequencies were $0.62,0.48$ and $0.072 \%$, respectively. Fusion induction by solutions containing $0.05 \mathrm{M}-\mathrm{CaCl}_{2} .2 \mathrm{H}_{2} \mathrm{O}, 0.05 \mathrm{M}$-glycine and $0.55 \mathrm{M}-\mathrm{NaCl}$ at $\mathrm{pH} 9.0$, without polyethylene glycol, gave only $0.001 \%$.

We thank Dr M. R. Davey for advice and help, and Professor E. C. Cocking and members of the ARC Group at Nottingham for helpful discussion on fusion methods. J. A. (Aspirant of the Belgian Nationaal Fonds voor Wetenschappelijk Onderzoek) acknowledges a fellowship in the European Science Exchange Programme awarded by the Royal Society, enabling him to carry out part of this work whilst at the Department of Botany, University of Nottingham.

\section{REFERENCES}

Adelberg, E. A., Mandel, M. \& Chen, C. C. (1965). Optimal conditions for mutagenesis by $N$-methyl- $N^{\prime}$-nitro- $N$-nitrosoguanidine in Escherichia coli $\mathrm{KI}$. Biochemical and Biophysical Research Communications r8, 788-795.

Anné, J., Eyssen, H. \& De Somer, P. (1974). Formation and regeneration of Penicillium chrysogenum protoplasts. Archives of Microbiology $98,159-166$.

Binding, H. \& WeBer, H. J. (1974). The isolation, regeneration and fusion of Phycomyces protoplasts. Molecular and General Genetics 135, 273-276.

Ferenczy, L., Kevei, F. \& Szegedi, M. (1975). Increased fusion frequency of Aspergillus nidulans protoplasts. Experientia 31, 50-52.

Ferenczy, L., Kevei, F. \& Zsolt, J. (1974). Fusion of fungal protoplasts. Nature, London 248, $793-794$.

Heagy, F. C. \& Roper, J. A. (1952). Deoxyribonucleic acid content of haploid and diploid Aspergillus conidia. Nature, London $\mathbf{1 7 0}, 713$.

KaO, K. N. \& MichayluK, M. R. (I974). A method for high-frequency intergeneric fusion of plant protoplasts. Planta II5, 355-367.

Keller, W. A. \& Melchers, G. (I973). The effect of high pH and calcium on tobacco leaf protoplast fusion. Zeitschrift für Naturforschung 28c, 737-741.

Lemke, P. A. \& NAsh, C. H. (1972). Mutations that affect antibiotic synthesis by Cephalosporium acremonium. Canadian Journal of Microbiology 18, 255-259.

MacDonald, K. D., Hutchinson, J. M. \& Gillett, W. A. (1965). Heterozygous diploids of Penicillium chrysogenum and their segregation patterns. Genetica 36, 378-397.

Nüesch, J., Treichler, H. J. \& Liersch, M. (1973). The biosynthesis of Cephalosporin C. In Genetics of Industrial Microorganisms, vol. 2, pp. 309-334. Edited by Z. Vanek, Z. Hostalek and J. Cudlin. Amsterdam, London and New York: Elsevier. 
Peberdy, J. F. \& Gibson, R. K. (1971). Regeneration of Aspergillus nidulans protoplasts. Journal of General Microbiology 69, 325-330.

Pontecorvo, G. (1956). The parasexual cycle in fungi. Annual Review of Microbiology Io, 393-400.

Pontecorvo, G. \& Sermonti, G. (I954). Parasexual recombination in Penicillium chrysogenum. Journal of General Microbiology II, 94-104.

Vogel, H.J. (1964). Distribution of lysine pathways among fungi: evolutionary implications. American Naturalist $98,435-446$. 